\title{
Possibility of Integrating Stingless Bees (Tetragonula iridipennis) into Urban and Peri-urban Agriculture and Urban Forest: Outlook Study from Bangalore-Silicon Valley of India
}

\author{
Prem Jose Vazhacharickal $^{1 *}$, K. S. Jagadish ${ }^{2}$ and G. Eswarappa ${ }^{2}$ \\ ${ }^{1}$ Department of Biotechnology, Mar Augusthinose College, Ramapuram, Kerala, India \\ ${ }^{2}$ Department of Apiculture, University of Agricultural Sciences, GKVK, Bangalore, \\ Karnataka, India \\ *Corresponding author
}

\section{A B S T R A C T}

\section{Keywords}

Tetragonula iridipennis,

Urban and periurban agriculture,

Urbanization,

Terrace gardens,

Meliponiculture

Article Info

Accepted:

18November 2020

Available Online:

10December 2020

\begin{abstract}
In the context of increasing urbanization and globalization of agricultural production and marketing, localized food systems (LFS) have emerged as a theoretical framework to imagine and order methods to address the effects and impacts, In Bengaluru, India's "Silicon Valley" and one of its fastest growing cities, an increasing number of middle class residents are growing fruits and vegetables in their private spaces for home consumption. This article examines the possibilities of integrating stingless bees (Tetragonula iridipennis) in urban agriculture and urban forests across Bangalore. Urban gardening is considered as a middle class intervention into unsafe food systems and decaying urban ecologies; driven primarily by concerns about worsening food quality and safety. The tree diversity is found to rich Bangalore and considered as an urban forest with high species richness in parks and residential areas. An urban forestry study revealed 374 species with highest species diversity in parks (291) followed by residential areas and layouts (164) dominated by Polyalthia sp. and Pongamiaglabra. Urban agriculture and urban forest system in the Bangalore are ideal for stingless bee keeping, easily reared with limited space and care and provide a leisure time activity for the retired person, women and children. Moreover the possible pollination services offered by integrating these little bees cannot be foreseen.
\end{abstract}

\section{Introduction}

Stingless bees are eusocial insects like other honey bees and quite appreciated for the value of the honey, pollen as well as various ecosystem services. Meliponiculture is the beekeeping method of stingless bees usually undertaken by traditional communities or local people (Vazhacharickal and Jose, 2016). Honey, pollen and resin is an important income for the stingless bee farmer. Usually stingless bees were seen in building foundations, mud walls, stone walls and tree cervices. These bees got the name Tetragonula iridipennis due to triangular abdomen and iridescent wings. For building nest, they collect resins from trees which make them called as Dammer bees (Vazhacharickal and Jose, 2018). Much importance is given to the large scale 
production of Apis indica and Apis mellifera in Karnataka. Very little scientific studies were conducted in stingless bees in Bangalore (Roopa et al., 2020). Stingless bees were much far ahead of medicinal properties of honey, and plant pollination when compared to other honey bees.

\section{Urbanization}

Urbanization is rapid and historic transformation on a global scale where rural culture is being replaced by urban culture. Migration which plays a key role in rural to urban transitions, is mainly governed by push factors and pull factors (Cohen, 2006; Timalsina, 2007; Satterthwaite et al., 2010; Vazhacharickal, 2014). Urbanization brings spatial, economic, social, demographic and environmental changes with positive and negative aspects (Weber and Puissant, 2003; Nath, 2007; Vazhacahrickal, 2014). It was expected that $68 \%$ of the world population lives in the urban areas by the year 2050 (UN, 2019).

\section{Urban and peri-agriculture}

Urban and peri-urban agriculture (UPA) can be broadly defined as the production, processing and distribution of foodstuff from crop and animal production, fish, and ornamental flowers within and around urban areas" (Mougot, 2000). The acronym UPA has been introduced by the Food and Agricultural Organization (FAO), and UPA mainly focuses on perishable and highly valuable products in limited spaces (Nugent, 2000; De Zeeuw et al., 2007). The UPA fills the hunger gaps by enhancing the access and distribution of food in urban areas (LeeSmith, 2010). Currently, Urban agriculture is being practiced for meeting subsistence needs, as a market-oriented activity, for recreation, or as a combination of all these components.

\section{Urban and peri-urban agriculture: Bangalore scenarios}

Little is known about the various UPA productions systems in Bangalore. A study conducted by Gowda et al., 2012 on Magadi; one of the true peri-urban area with strong agricultural base show that the proportion of the net income from agriculture and livestock to the total income raised. The cooperative horticultural marketing by HOPCOMS in Bangalore is an example of collective marketing by farmers in the peri-urban areas. Urban agriculture in Bangalore flourish with the support of Garden City Farmers Trust; NGO which support urban farming, which is similar to Dr.Doshi's city garden methods suitable to reduced spaces such as balconies and terraces which depend on locally available materials like sugarcane wastes, polyethylene bags and household organic wastes and are targeted towards mainly domestic consumption ((Vazhacharickal and Buerkert, 2011). The need for housing increases the value of agricultural land in urban and peri-urban areas and leads to their rapid transformation (Vazhacharickal, 2014; Hoffmann et al., 2017).

\section{Localized food systems}

In the context of increasing urbanization and globalization of agricultural production and marketing, localized food systems (LFS) have emerged as a theoretical framework to imagine and order methods to address the effects and impacts. Growing cities can have profound positive or negative impacts on their surrounding food producing areas and trend that is most often observed, negative impacts on food and nutrition security resulting especially from increasing pressure on the natural resources required to feed the urban population (Grinspan, 2015). Another opportunity of UPA to contribute to the localization of the food system rises from its 
direct access to urban consumers and markets, which facilitates the expansion of direct marketing arrangements.

\section{Middle class urban gardening}

Gardening is becoming fashionable among people of the new middle-classes and Urban gardening has long been a working-class practice in places such as Bangalore (Fig. 2; Frazier, 2018).

India's new middle-class is elusive and consists of a heterogenous group of people who are generally high educated and welltravelled, and who carve out a social position between elite and working classes through consumption and leisure practices (Fernandes and Hel-ler, 2006; van Holstein, 2019).

\section{Organic Terrace Gardeners (OT Gians)}

An increasing number of middle class residents in Bengaluru are growing fruits and vegetables for home consumption, motivated primarily by concerns about worsening health and food safety conditions, and secondarily by declining green spaces in the city. Organic terrace gardeners, most of whom self-describe as "OTGians", a title that originated with the Organic Terrace Gardening (OTG) Facebook group.

OTGians have created a vibrant community dedicated to sharing resources and knowledge about urban gardening, with the goal of reworking existing relations of food production and consumption in the city. Communication among members is mainly mediated through the group's FaceBook page, and group identity is largely built on that platform (Grinspan, 2015; Frazier, 2018).

\section{Garden City Farmers Trust (GCF)}

Garden City Farmers Trust (GCF) is officially registered as trust and started in activity way back in the year 1995 with the promotional work of its founder, Dr. B. N. Vishwanath. GCF's current major focus area is on promoting organic terrace and home gardening in the city of Bangalore by conducting trainings and workshops, connecting practitioners and resources, and promoting awareness of urban food growing through national and state-level seminars with a motto "Grow What You Eat, and Eat What You Grow". The event "Oota From Your Thota" (or Food From Your Garden) is a quarterly event with a two-fold purpose: to bring urban practitioners and other interested people together to share their experiences and knowledge; and to connect urban gardeners and re-source provider (Grinspan, 2015; Frazier, 2018).

\section{Balcony and terrace gardens in Bangalore}

The Kannada term kaithota (literally "hand garden") refers to kitchen gardens that are common in rural house-holds, where women plant a few fruits and vegetables for consumption and flowers for religious worship near the edges of their home. The term kaithota and the broader term thota, meaning garden or plantation, are sometimes used to describe urban home gardens. Most of the urban gardens have their garden on the terrace/balconies of their house or apartment of flats. Usually majority of the terrace gardens are container gardens which focus on ornamental plant and food plants especially vegetables, aromatic plants and fruit trees. The major input use and provisions include compost (kitchen waste and other brought outside), water (household supply), containers (plastic drums, vegetable wooden crats, used cement bags, old tyres and various styrofoam packing materials), cow dung and urine, neemoil cake and coco peat (Grinspan, 2015; Frazier, 2018). 
Parks, community spaces, institutions and avenues: Tree diversity

The tree diversity is found to be rich Bangalore and considered as an urban forest with high species richness in parks and residential areas. An urban forestry study revealed 374 species with highest species diversity in parks (291) followed by residential areas and layouts (164). Polyalthia $s p$. and Pongamia glabra are the most dominant species in parks though their relative density is lesser in the larger parks. Polyalthia $s p$. is also dominant in institutions and offices to the extent of a relative density of 21 to $34 \%$. Institutionsare dominated by fast growing species (Polyalthia longifolia, Grevillea robusta, Bauhinia variegata), decorativetrees (Delonix regia, Tabebuia argentea) and shade-givingtrees (Samanea saman) (Sudha and Ravindranath, 2000).

Flat and apartments, open gardens and community spaces

Sudha and Ravindranath (2000)identified a total of 164 species in different residentialareas in Bangalore, the 10 dominant species accounted for $58 \%$ of the trees. The predominant species in the higher strata are Cocos nucifera, Murraya koenigii, Psidium guajava and Polyalthialongifolia. In the lower strata, the dominant species are Cocos nucifera, Moringa oleifera, Musa paradisiaca and Mangifera indica (Sudha and Ravindranath, 2000).

\section{Trees in house compounds}

The top 15 predominant species in compounds of residences account to $77 \%$ of the total trees in compounds. Cocos nucifera is the predominant species, accounting for
18\%, followed by Murraya koenigii, Musa paradisiaca. Moringa oleifera and Carica papaya. Polyalthia longifolia and Michelia champaca, which are ornamental and fruit yielding varieties includes, Cocos nucifera, Carica papaya, Psidium guajava, Mangifera indica, Punica granatum, Annona squamosa, Citrus limon and Artocarpu sintegrifolius. Two species are used in cooking; Moringa oleifera asa vegetable and Murraya koenigii leaves for seasoning. Ricinus communis grows more as a weed in the compounds of houses of the higher income group and also in the wastelands around houses in the lower income areas (Fig. 2; Sudha and Ravindranath, 2000).

\section{Avenue trees in residential areas}

The avenue trees account for $28 \%$ of the trees in the residential land-use category. Of the 87 species, the top 15 tree species account for $80 \%$ of the total avenue trees. The trees most preferred by the Social Forestry Scheme are Michelia champaca, Bauhinia variegate and Pongamia glabra. Moringa oleifera is found in abundance in the lower income residential areas along avenue (Sudha and Ravindranath, 2000).

\section{Pollen and nectar sources for stingless bees}

Stingless bees collect nectar and pollen from a variety of plant species especially woody trees, fruit trees, ornamental and medical plants, weed plants and vegetable crops. Some of the plants supply nectar and pollen through-out the year while others are only seasonal. Due to the small size, the stingless bees can collect nectar and pollen from very small flowers where other honey bee species fail to do. 
Fig.1Description of the stingless bees across Bangalore a) natural habitat on mud walls; b) habitat on stone walls; f) colony showing brood and stored honey and pollen
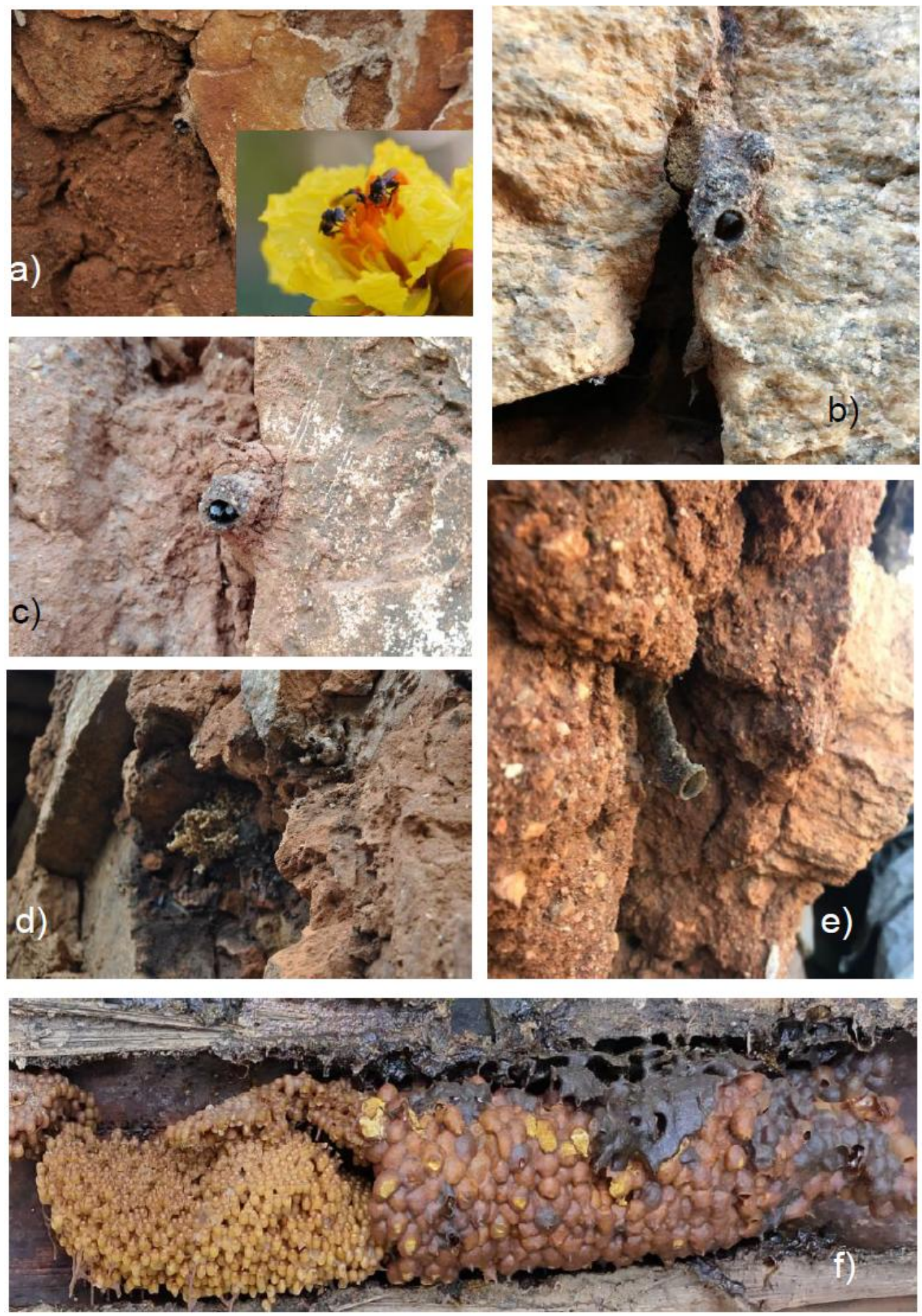
Fig.2 Description of the urban agriculture and urban forest across Bangalore a) and d) avenue trees in GKVK and residential area; b: community park in flats; c) Ricinus communis in waste lands; e) and g) balcony gardens; f) terrace garden

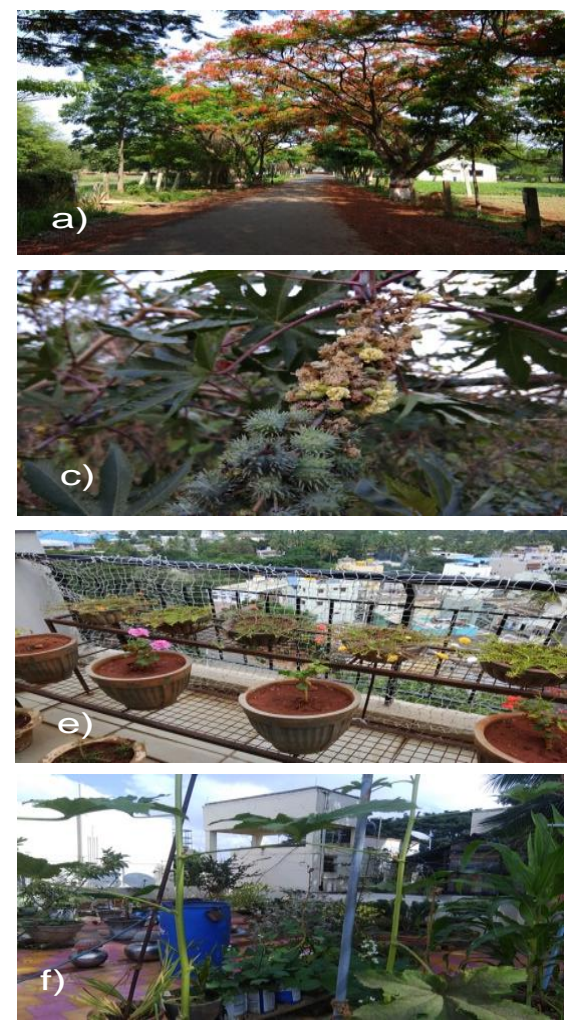

Natural habitat of stingless bees in Bangalore

The stingless bees are found naturally abundant in stone walls, mud walls wooden logs, telephone posts, GI pipes in and around various areas in Bangalore (Fig. 1). They are abundant in GKVK campus, old churches made with stone and serial anthropogenic habitats. These are natural feral colonies which cannot be easily collected un-less special education techniques or destructive methods used (Vazhacharickal and Jose, 2016; 2018).

Integration ofstingless bees in urban agriculture and urban forest

Stingless bees could be successfully integrated into the urban farming systems

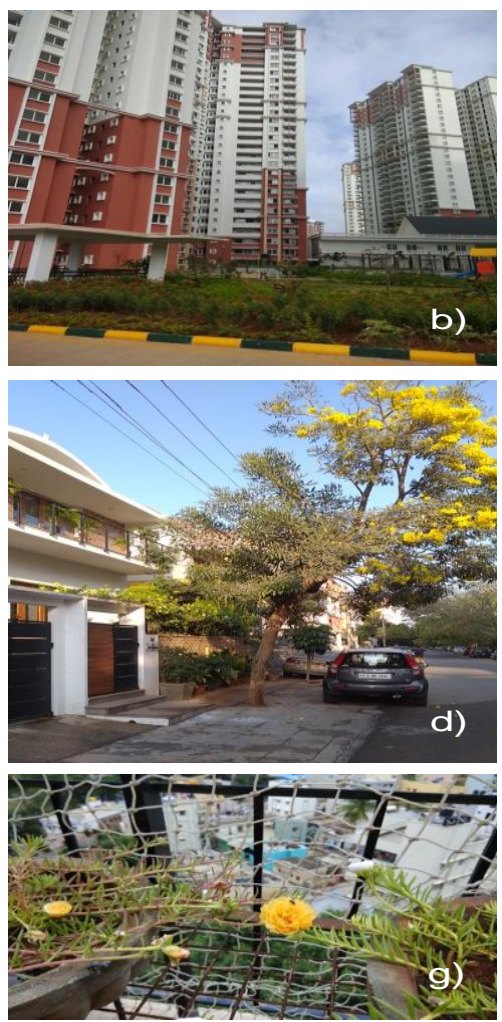

without much complications especially in balcony, terrace as well as kitchen gardens. In addition, they could be also use to serve the urban forests especially parks, roadside avenues, temples and other worshiping places, institutions with campus and even in the flats with community parks and gardens. The stingless bees needs minimum space and attention and could be easily handled by women, children and aged persons without any difficulty. The stingless bees could be placed on balconies, open terraces or in the garden which could marginally improve pollination, crop yield and ecosystem services. A single stingless bee colony can yield 400-500 g of pure honey which can fetch to 18-20 US\$ per yield. Moreover, while integrating stingless bees into the urban environment; provide leisure time activity and mental enchantment for the retired persons 
and collection pure home honey with high medical properties.

\section{Possible outcomes of integration}

The Urban agriculture and urban forest system in the Bangalore are ideal for stingless bee keeping. These pro-vide a wide variety for foraging sources for the stingless bees. Currently these floral resources are being underutilized; utilized only for aesthetic beauty and integration of stingless bees will definitely utilize the various floral re-sources. The pollination services proved by these bees will have a definitely impact on the urban agriculture productivity, size and quality of the fruit and better utilization the resources.

In conclusion the urban agriculture and urban forest system in the Bangalore are ideal for stingless bee keeping and provide them with nectar and pollen. Since natural feral stingless bees can been in many places in and around Bangalore, they may be considered as resilient to the urban environment.

The integration of stingless bees will definitely improve the pollination in the urban gardens and urban forest which in turn have a clear impact of the fruit productivity, fruit size and seed setting. Stingless bees could be easily reared with limited space and care and provide a leisure time activity for the retired person, women and children. More over the possible pollination services offered by integrating these little bees cannot be foreseen in the Silicon valley of India.

\section{Acknowledgment}

This outlook study will not be possible by the encouragement and support from Dr. K. B. Umesh, Dr. Andreas Buerkert, Dr.Prasanna Kumar P. S, Dr.Veerabhadrappa Bellundagi, Dr.Nagesh N. C and Dr.Catrin Westphal.

\section{References}

Cohen, B., 2006. Urbanization in developing countries: current trends, future projections, and key challenges for sustainability. Technology in Society 28(1): 63-80.

De Zeeuw, H., van Veenhuizen, R. and Dubbeling, M. 2011. The role of urban agriculture in building resilient cities in developing countries. The Journal of Agricultural Science 149(S1): 153-163.

Fernandes, L., and Heller, P. 2006. Hegemonic aspirations: New middle class politics and India's democracy in comparative perspective. Critical Asian Studies, 38(4): 495-522.

Frazier, C. 2018. "Grow what you eat, eat what you grow": urban agriculture as middle class intervention in India. Journal of Political Ecology, 25(1): 221-238.

Gowda, U. R., Chandrakanth, M. G., Srikanthamurthy, P. S., Yadav, C. G., Nagaraj, N., and Channaveer. 2012. Economics of Peri-Urban Agriculture: Case of MagadiOff Bangalore. Economic and Political Weekly, 75-80.

Grinspan, D. 2015. Urban gardening practices in Bangalore: towards a more localized food system? Independent Study Project (ISP) Collection. 2079.

Hoffmann E, Jose M, Nölke N. and Möckel T 2017. Construction and use of a simple index of urbanization in the rural-urban interface of Bangalore, India. Sustainability, 9 (11): 1-21.

Lee-Smith, D. 2010. Cities feeding people: an update on urban agriculture in equatorial Africa. Environment and Urbanization 22(2): 483-499.

Mougeot, L.J.A. 2000. Urban agriculture: definition, presence, potentials and risks. In: Bakker, N., Dubbeling, M., Guendel, S., SabelKoschella, U. and De Zeeuw, H. (Eds.). Growing Cities, Growing Food: Urban Agriculture on the Policy Agenda.Deutsche Stiftungfürinternationale Entwicklung 
(DSE), Feldafing, Germany, pp. 1-42.

Nath, V. 2007. Urbanization, urban development, and metropolitan cities in India. Concept Publishing Company, New Delhi, India.

Nugent, R. 2000. The impact of urban agriculture on the household and local economies. In: Bakker, N., Dub-beling, M., Guendel, S., SabelKoschella, U. \& De Zeeuw, H. (Eds.). Growing Cities, Growing Food: Urban Agri-culture on the Policy Agenda.Deutsche Stiftungfürinternationale Entwicklung (DSE), Feldafing, Germany, pp. 67-98.

Roopa, A. N., Gowda, G., Eswarappa, G. and Vazhacharickal, P. J. 2020.Bio-ecology of Stingless bees, Trigonairidipennis Smith. (Hymenoptera: Apidae) in GKVK campus: an overview. Amzon Publishers, NY, USA.

Satterthwaite, D., McGranahan, G. and Tacoli, C. 2010. Urbanization and its implications for food and farming. Philosophical Transactions of the Royal Society B: Biological Sciences 365(1554): 2809-2820.

Sudha, P., and Ravindranath, N. H. 2000.A study of Bangalore urban forest. Landscape and Urban Planning, 47(1-2): 47-63.

Timalsina, K.P. 2007. Rural urban migration and livelihood in the informal sector: A study of street vendors of Kathmandu metropolitan city, Nepal. Norwegian
University of Science and Technology, Trondheim, Norway.

UN 2019. World Urbanization Prospects - The 2018 Revision, United Nations (UN), NY, USA

van Holstein, E. 2019. The social boundary work of new middle-class organic gardeners in Bangalore, India.Urban Forestry \& Urban Greening, 44, 126432.

Vazhacharickal, P. J and Jose, S. 2016. Nesting behavior and habitats of the stingless bee Trigonair idipennis Smith in Kerala. Amzon Publishers, NY, USA.

Vazhacharickal, P. J and Jose, S. 2018. Stingless bees culture (Meliponiculture) in Kerala: hand book for farmers. Amzon Publishers, NY, USA.

Vazhacharickal, P. J. 2014. Characterization of urban and peri-urban agriculture production systems and soil heavy metal signatures in the Mumbai metropolitan Region, India.CuvillierVerlag, Goettingen, Germany.

Vazhacharickal, P. J. andBuerkert, A. 2011. Sustainable cities: an overview of the urban and peri-urban agricultural production in Mumbai Metropolitan Region (MMR). Leituras de Economia Política (19): 69-87.

Weber, C. and Puissant, A. 2003. Urbanization pressure and modelling of urban growth: example of the Tunis Metropolitan Area. Remote Sensing of Environment 86(3): 341-352.

\section{How to cite this article:}

Prem Jose Vazhacharickal, K. S. Jagadish and Eswarappa, G. 2020. Possibility of Integrating Stingless Bees (Tetragonula iridipennis) into Urban and Peri-urban Agriculture and Urban Forest: Outlook Study from Bangalore-Silicon Valley of India. Int.J.Curr.Microbiol.App.Sci.9(12): 2662-2669. doi: https://doi.org/10.20546/ijcmas.2020.912.315 